ARTICLE

https://doi.org/10.1038/s41467-019-12396-y

\title{
Organic sulfur was integral to the Archean sulfur cycle
}

\author{
Mojtaba Fakhraee (iD ${ }^{1 \star} \&$ Sergei Katsev (10) ${ }^{1,2 \star}$
}

The chemistry of the Early Earth is widely inferred from the elemental and isotopic compositions of sulfidic sedimentary rocks, which are presumed to have formed globally through the reduction of seawater sulfate or locally from hydrothermally supplied sulfide. Here we argue that, in the anoxic Archean oceans, pyrite could form in the absence of ambient sulfate from organic sulfur contained within living cells. Sulfides could be produced through mineralization of reduced sulfur compounds or reduction of organic-sourced sulfite. Reactive transport modeling suggests that, for sulfate concentrations up to tens of micromolar, organic sulfur would have supported 20 to $100 \%$ of sedimentary pyrite precipitation and up to $75 \%$ of microbial sulfur reduction. The results offer an alternative explanation for the low range of $\delta^{34} \mathrm{~S}$ in Archean sulfides, and raise a possibility that sulfate scarcity delayed the evolution of dissimilatory sulfate reduction until the initial ocean oxygenation around $2.7 \mathrm{Ga}$.

\footnotetext{
${ }^{1}$ Large Lakes Observatory, University of Minnesota Duluth, 2205 E. 5th St., Duluth, MN 55812, USA. ${ }^{2}$ Department of Physics and Astronomy, University of Minnesota Duluth, Duluth, MN 55812, USA. *email: fakhr008@umn.edu; skatsev@d.umn.edu
} 
S ince the beginning of Life, sulfur cycled between the geosphere and biosphere as an essential component of all living matter. Organic S-bearing molecules, such as amino acids cysteine and methionine, have been ubiquitous throughout the planet's history ${ }^{1,2}$ and even have been detected on Mars $^{3}$. In modern oceans, however, the petagram inventory ${ }^{4}$ of dissolved organic sulfur and the estimated $0.2-0.4 \mathrm{Pg}$ of particulate organic sulfur ${ }^{4}$ are dwarfed by the $10^{9} \mathrm{Pg}$ of inorganic sulfate, which at 28 $\mathrm{mM}$ is the second most abundant anion in seawater. At these concentrations, the geologically important cycling of sulfur through sulfate reduction, precipitation of pyrite, and reoxidation of sulfides is carried out overwhelmingly by inorganic sulfur. Abundant sulfate, however, was rare through most of the Earth's history. Proterozoic oceans were likely characterized by sub-mM to low $\mathrm{mM}$ concentrations ${ }^{5,6}$, and low-sulfate conditions returned episodically throughout the Phanerozoic ${ }^{7}$. In the Archean, before the beginning of ocean oxygenation 2.7-2.5 billion years ago ${ }^{8,9}$, marine sulfate was scarce in coastal and surface pelagic ocean, at no more than tens of $\mu \mathrm{M}^{9,10}$, and likely absent in ferruginous deep waters. The cycling of sulfur under these conditions was very different from the one in the modern ocean, and freshwater systems, particularly stratified lakes, are commonly used as better analogs ${ }^{10}$. Recent work ${ }^{11}$ has demonstrated that in low-sulfate lakes $(<100 \mu \mathrm{M})$, mineralization of organic sulfur (OS) supplies a significant portion of the substrates for microbial sulfate reduction $^{12}$, and a significant fraction of sulfide is traceable to an organic source ${ }^{13,14}$. In the well-oxygenated sediments of oligotrophic Lake Superior ${ }^{11}$, for example, mineralization of the settled particulate organic sulfur causes accumulation of sulfate in the upper oxidized layer, often in excess of the water column concentrations, and supports over $80 \%$ of sulfate reduction in the deeper anoxic sediment. Paradoxically, the organic component has not been considered in reconstructions of the Early Earth sulfur cycling. The histories of atmospheric oxygen and oceanic sulfate are widely inferred from the records of sulfur isotopes preserved in pyrites ${ }^{9,15}$, but non-hydrothermal pyrite formation was considered only from seawater sulfate ${ }^{10,16}$ or elemental sulfur ${ }^{17}$

Here, we argue that organic sulfur must have been a significant component of the early biogeochemical cycling, and its mineralization provided at least two major pathways to pyrite, which could operate even in sulfate-free environments. The effects of these processes on the geochemical and isotopic compositions of sedimentary sulfides are consistent with available evidence and warrant a re-evaluation of the presently accepted interpretations of the geochemical and isotopic proxies.

\section{Results}

Arguments for the significance of organic sulfur. Sulfur makes up about $1 \%$ of dry weight of aquatic organisms ${ }^{18}$. It occurs at lower oxidation states in proteins such as amino acids cysteine and methionine, in coenzymes (e.g., coenzyme A, biotin, thiamine), as iron-sulfur clusters in metalloproteins, and in bridging ligands (e.g., in cytochrome $c$ oxidase) ${ }^{2}$. Higher oxidation state compounds, such as sulfonates $\mathrm{R}-\mathrm{SO}_{3}-\mathrm{H}$, sulfones $\mathrm{R}-\mathrm{SO}_{2}-\mathrm{R}$, and organo-sulfates, can be found in lipids (e.g., Sulfoquinovosyl diacylglycerols) and are components of cell walls and photosynthetic membranes. Molar S:C ratios in modern plankton ${ }^{18}$ typically range between 0.003 and 0.01 , with freshwater values ${ }^{19}$ being more varied than in marine environments because of a wider range of geochemical conditions. Archean S:C ratios likely spanned a similar range, or were even higher if sulfolipids could be used in place of phospholipids ${ }^{20,21}$ to alleviate P limitation ${ }^{22}$. The Archean organic sulfur pool was likely dominated by reduced compounds $^{23}$, which are thermodynamically easier to assimilate under anoxic conditions ${ }^{24}$. Assimilation of sulfate requires energy even at the stage of cellular uptake by sulfate-binding proteins ${ }^{24}$, and sulfate $(+6)$ is rare in prokaryotic cells ${ }^{24}$, whereas key molecules contain sulfites $(+4)$ or sulfonates $(+4)^{25,26}$. Reduced sulfur appears in evolutionary key molecules such as methionine, cysteine, cystine, coenzymes $\mathrm{M}$ and acetyl $\mathrm{CoA}$, aromatic sulfur and disulfides, and in primitive metabolic processes such as $S$ oxidation in anoxygenic phototrophs. Hydrothermally supplied hydrogen sulfide $(+2)$ in the presence of $\mathrm{CO}_{2}$ could form thiols, critical coenzymes, $\mathrm{CS}_{2}$ and dimethyldisulfide $\mathrm{e}^{1,27,28}$

Mineralization of organic sulfur compounds would recycle a significant portion of this organic pool as inorganic sulfur, making it available for processes that in the modern oceans are supported by seawater sulfate. Hydrolysis and mineralization of oxidized organic sulfur $\left(\mathrm{R}-\mathrm{SO}_{3}-\mathrm{H}\right)$ would generate sulfite $\left(\mathrm{SO}_{3}{ }^{2-}\right)$, which in Archean oceans would add to the pool generated by the dissolution of volcanic $\mathrm{SO}_{2}$ (Fig. 1). While in the modern environments sulfite is efficiently converted to sulfate by oxidation or disproportionation ${ }^{29,30}$, in an anoxic ancient water column such conversion could take substantially longer, especially if disproportionation ${ }^{31,32}$ was limited by low concentrations or low capacity for microbial catalysis. Mineralization of oxidized organic fractions would supply sulfite throughout the ocean depths that were reached by the inefficient Archean carbon pump $^{33}$, but also, importantly, would generate it in sediments from any exported organic matter. Sulfite is readily utilized by sulfur reducing bacteria for dissimilatory reduction, and thermodynamically provides more energy for cell metabolism than sulfate $^{34}$. Its liberation in a sulfate-depleted ocean would make it available as a substrate for sulfur reducing metabolisms. In a world that lacked a strong oxidant like molecular oxygen, the redox cycling of sulfur could potentially rely on sulfite as the dominant oxidized species. This possibility is supported by genetic evidence that points to the evolution of sulfite reducing metabolisms as early as $3.7 \mathrm{Ga}$, while genes for sulfate reduction appear later ${ }^{23,35}$. Some Archaea are known to reduce sulfite while not being able to reduce sulfate, and some auxotroph bacteria are known to utilize sulfonate OS directly ${ }^{4,36}$.

Mineralization of the reduced organic S pool (R-SH) would provide an even more important input of inorganic sulfur. Such mineralization generates hydrogen sulfide, which under

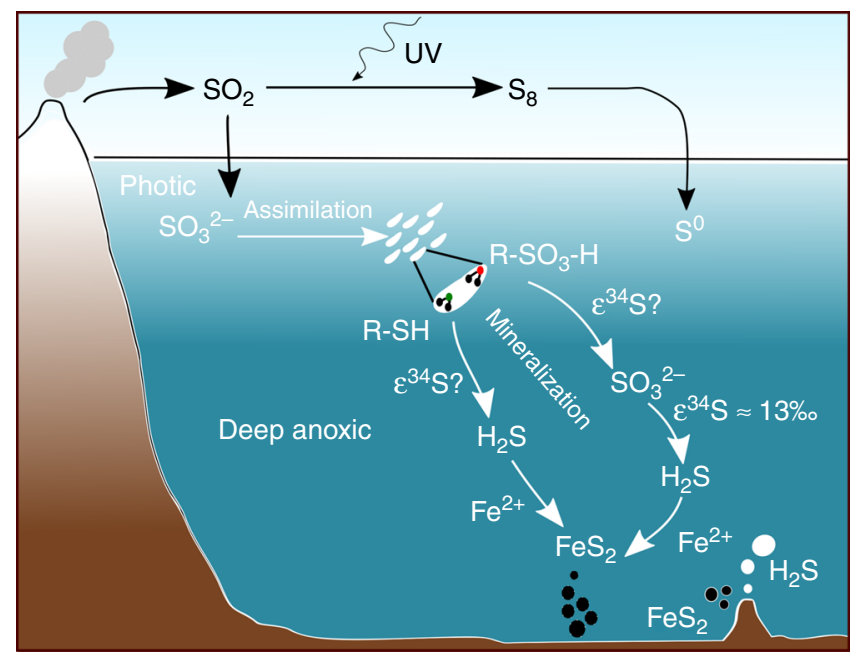

Fig. 1 Archean sulfur cycle with contribution from organic sulfur (OS). Mineralization of OS serves as a source of both oxidized (up to +4 ) and reduced sulfur in the ferruginous deep-water column and sediments. In the Neoarchean, the availability of free oxygen would increase the role of sulfate $(+6)$ 
ferruginous Archean conditions would react with dissolved iron $\left(\mathrm{Fe}^{2+}\right)$ to form iron sulfides, bypassing the traditionally assumed pathway of sulfate reduction.

The geochemical fluxes and transformation rates sustained by the mineralization of organic sulfur must have been quantitatively significant. The inventory and cycling rates of organic matter are poorly constrained for the Archean, but assuming, as an order of magnitude estimate 33,37 , that respiration in the anoxic Archean water column was $5 \%$ of the value found in the modern ocean below the photic zone ${ }^{38}$, mineralization rates were $\sim 100 \mathrm{Tmol} \mathrm{C}$ year ${ }^{-1}$, regenerating $0.3-1 \mathrm{Tmol} \mathrm{S}^{\mathrm{s}} \mathrm{year}^{-1}$ of inorganic sulfur. This is higher than the estimated flux of sulfur from hydrothermal settings ${ }^{39}\left(0.2-0.5 \mathrm{Tmol} \mathrm{S}\right.$ year $\left.^{-1}\right)$ and comparable to the estimated Archean pyrite burial flux ${ }^{40,41}(\sim 0.1-1$ Tmol S year $^{-1}$ ). Through reduction of oxidized OS and direct release of hydrogen sulfide from reduced OS, followed by a nearly quantitative conversion to pyrite under ferruginous conditions, this re-mineralization could generate a significant portion of the pyrite that was eventually preserved in Archean sediments. Like sulfate reduction, pyrite precipitation likely occurred primarily in organic rich coastal regions, including microbial mats ${ }^{42}$, where the contributions from organic sulfur could have been high. For a concentration of total inorganic sulfur in the ocean water on the order of $10 \mu \mathrm{M}^{10}$, mineralization at the rate of $0.3-1$ Tmol S year $^{-1}$ implies that the entire oceanic pool of sulfur could cycle through the organic pool in under 10,000 years. In surface sediments (e.g., at $\sim 0.1 \%$ organic carbon content and the $\mathrm{S}: \mathrm{C}$ ratio of 0.003$)$, the abundance of organic sulfur $(\sim 100 \mu \mathrm{mol} \mathrm{S}$ per liter of sediment, assuming typical porosity and bulk sediment density) would compete with the low $\mu \mathrm{M}$ availability ${ }^{10}$ of inorganic S from the overlying water column, and could be the only source of reactive sulfur in deeper sediment.

Generation of sulfite and dissolved sulfide from organic S within the sediments and water column radically changes the picture of the Archean sulfur cycling. Traditional view and previous numerical models $9,10,16$ assumed that sulfate was transported from the surface ocean into the deep waters or sediments where it underwent microbial reduction to sulfide, which in the presence of ferrous iron precipitated to eventually form pyrite. In contrast, the oxidized inorganic sulfur compounds produced from the oxidized fraction of OS could support $S$ reduction even when sulfate was absent from ambient water. Likewise, the hydrogen sulfide produced from the reduced OS could generate pyrite even in the absence of sulfate reduction.

Reaction transport modeling. To illustrate the potential role of organic sulfur, we used a vertically resolved diffusion-reaction model, which we adapted from ref. ${ }^{11}$ and applied to Archean conditions $^{9}$ (see Methods section). For the sake of concreteness, we performed simulations in sediments. While the transport mechanisms in water column may be more varied and threedimensional, similar arguments should apply, at least qualitatively, to a water column where sulfate and particulate OS reach the anoxic ferruginous deep waters from the surface mixed layer ${ }^{10}$. For a more straightforward comparison with previous models that did not consider sulfite, and to extend the results to potentially oxygenated conditions of the Neoarchean, the model uses sulfate as the oxidized form of inorganic sulfur; this does not change the generality of the argument. Mineralization of reduced OS was assumed in the model to generate hydrogen sulfide (Supplementary Table 1). The ratio of oxidized to reduced OS within organic matter was set to $40 \%: 60 \%$ as a reference value and varied in a sensitivity analysis (Supplementary Tables 2 and 3). Similarly to previous work ${ }^{11}$, the model calculated the fraction of the sedimentary sulfate reduction that was supported by OS mineralization, and the fraction of pyrite that was formed through the mineralization of reduced OS (Fig. 2). The latter fraction provided a lower limit for the OS contribution to pyrite formation, as additional pyrite could originate from mineralization of the oxidized OS pool upon its reduction in sediment. These fractions were calculated from the respective ratios of the depth-integrated rates for OS mineralization, sulfate reduction, and pyrite precipitation (Eqs. 1 and 2). As the presence of methane in sediment porewaters may potentially influence the a

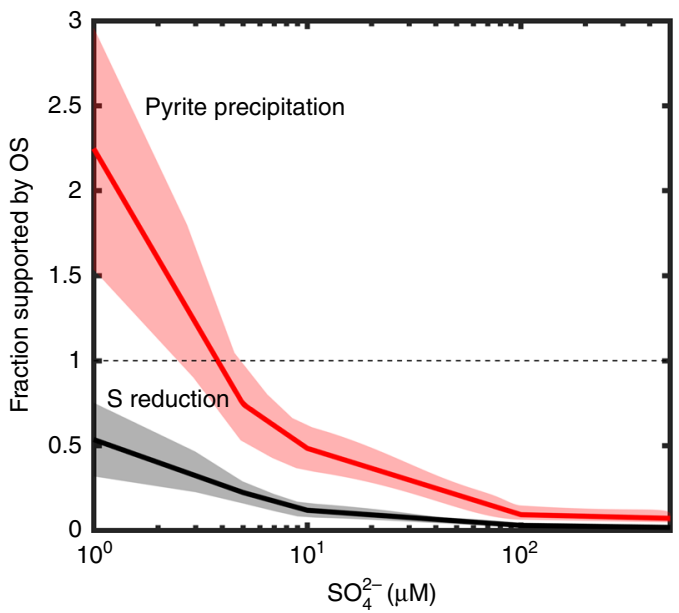

b Fraction supported by OS
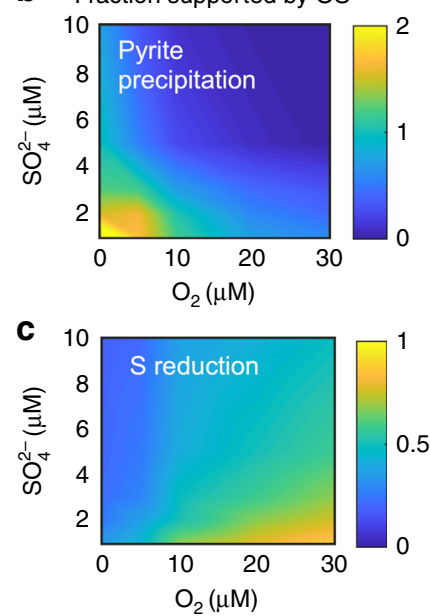

Fig. 2 Contribution of organic sulfur to $S$ reduction and pyrite precipitation. a As a function of sulfate (sulfite) concentration under anoxic conditions. Shaded bands reflect the corresponding $\pm 1 \sigma$ ranges obtained in the sensitivity analysis (see Methods section). $\mathbf{b}, \mathbf{c}$ The same, in presence of oxygen. The fraction of supported $\mathbf{S}$ reduction was calculated as the ratio of the depth integrated rates of oxidized OS mineralization and sediment $\mathbf{S}$ reduction. The latter was corrected for the fraction of sulfate reduction supported by elemental S disproportionation and sulfide reoxidation. The fraction of supported pyrite precipitation was calculated as the ratio of the depth integrated rates of reduced OS mineralization and Fe sulfide precipitation. The ratio was corrected for elemental $\mathrm{S}$ disproportionation and the fraction of produced hydrogen sulfide that becomes unavailable for precipitation because of aerobic oxidation (see Supplement). Values greater than 1 correspond to a situation where excess hydrogen sulfide diffuses out of the sediment. Sediment was assumed to contain $0.5 \%$ of organic carbon by dry weight, with the molar S:C ratio of 0.005 
cycling of sulfur, the robustness of the model's conclusions was tested by including the methane cycle (see Methods section). At the considered low concentrations of sulfate, this modified the inferred ranges for the OS contributions to pyrite formation and sulfate reduction (Fig. 2) by less than $5 \%$.

Simulations reveal that, for $<50 \mu \mathrm{M}$ of sulfate in Archean seawater ${ }^{9,10}$, between 20 and $100 \%$ of all pyrite precipitated in sediment would originate from organic sulfur (Fig. 2, Supplementary Figs. 1 and 2). For $<10 \mu$, a significant fraction of pyrite may form from OS even at low organic $\mathrm{S}: \mathrm{C}$ ratios and for organic carbon concentrations as low as $0.1 \%$ (Supplementary Fig. 3). Mineralization of oxidized OS supports between 5 and $75 \%$ of the total sedimentary S reduction. The OS contributions remain significant for sulfate concentrations up to $>100 \mu \mathrm{M}$ (Fig. 2, Supplementary Fig. 1), at which point the seawater sulfate becomes the dominant source. If these sulfate concentrations were not achieved in the oceans until the later stages of the Great Oxidation Event ${ }^{9}$, the organic component of the sulfur cycle must have remained important throughout the Archean Eon. At low sulfate concentrations, the presence of oxygen enhances the organic sulfur contribution to sulfate reduction (Fig. 2). Though oceans throughout the Archean Eon are thought to have been predominantly anoxic, Neoarchean sediments in shallow coastal regions could have been exposed to concentrations of up to tens of $\mu M^{8,9}$. Being a more potent electron acceptor, oxygen decreases the sediment demand for seawater sulfate, making the insediment generation of oxidized S proportionately more important. The (percentage) contribution of OS to sulfate reduction increases also with the sediment organic matter content, as organic matter supports OS mineralization rates, even though it also stimulates sulfate reduction and the drawdown of sulfate from overlying water (Supplementary Fig. 3). In the Neoarchean, environments with higher oxygen concentrations and higher organic carbon fluxes could be found in oxygenated oases in shallow coastal regions ${ }^{8,43}$ where oxygenic photosynthesis fueled higher primary productivity, sedimentation rates were high, and most pyrite is thought to have originated.

\section{Discussion}

The contribution of organic component to pyrite formation profoundly changes the accepted interpretations of the Archean isotopic signals. Microbial sulfate reduction depletes the sulfide in ${ }^{34} \mathrm{~S}$, generating isotopic differences between the seawater sulfate and sediment pyrite $\Delta^{34} S_{\mathrm{FeS} 2}=\delta^{34} S_{\mathrm{SO} 4}-\delta^{34} \mathrm{~S}_{\mathrm{FeS} 2}$. The limited range of $\Delta^{34} S<10 \%$ o throughout the Archean is viewed as a consequence of low sulfate, which restricted sulfate reduction ${ }^{10,16}$. The $\Delta^{34} S_{\mathrm{FeS}}$ range is further limited by the Rayleigh distillation: the sulfate diffusing downward into the sulfate reduction zone becomes isotopically heavier with depth and the $\delta^{34} S$ of the produced sulfide trends towards the $\delta^{34} S$ of the original sulfate. The possibility of pyrite formation from the OS-derived sulfur means that sulfidic rocks do not necessarily record the evidence of these processes but instead reflect a more complex mixture of isotopic influences. Sulfite produced at some depth within the sediment column may be reduced at the same depth, without undergoing Rayleigh distillation ${ }^{32}$. As isotopic fractionations associated with the reduction of sulfite are small ${ }^{32,44}(13 \pm 7 \%$ ) compared with those for sulfate $(>30 \%$ ), they are consistent with observations of small $\Delta^{34} \mathrm{~S}$. The hydrogen sulfide produced from the more abundant reduced OS compounds would generate solid sulfides, bypassing microbial reduction. Rather than carrying an isotopic signature of redox processes, these sulfides could instead carry the isotopic signal of hydrolysis. The magnitudes of the fractionations during hydrolysis of organic sulfur are not well constrained, but thermodynamic considerations $\mathrm{s}^{45}$ and laboratory investigations ${ }^{46}$ limit them to less than $17 \%$, consistent with small observed $\Delta^{34} S$. Small isotopic fractionations are similarly consistent with the evidence in modern sediments where care was taken to analyze the hydrolyzable fraction of organic sulfur ${ }^{47,48}$. In particular, depth variations in the isotopic composition of hydrolyzable organic sulfur pool seem to indicate a preferential loss of isotopically light organic sulfur during the early stages of diagenesis ${ }^{47}$. Incorporating these considerations into an isotopic model of sulfur diagenesis (modified from ref. ${ }^{11}$; Supplementary Fig. 4) suggests that the $\Delta^{34} S_{\mathrm{FeS}}$ values in Archean pyrites could be increased by the contributions from organic sulfur (assuming fractionation during hydrolysis of $15 \%$ ) only by a few permil (Supplementary Fig. 5), even when most of the pyrite originates from organic sulfur (Fig. 2a). The $\Delta^{33} \mathrm{~S}_{\mathrm{FeS}}$ values of pyrite are essentially not affected $(<0.5 \%)$ when the $\Delta^{33} S$ composition of organic sulfur is similar to that of seawater sulfate.

The ambiguity of isotopic interpretations calls for a reevaluation of the ancient sulfur cycling. Mineralization of S-bearing organic matter provided sulfur-reducing organisms not only with an electron donor in the form of organic carbon, but also with an electron acceptor, while mineralization of the reduced OS could supply hydrogen sulfide directly. As $\Delta^{34} S_{\mathrm{FeS}}$ records are equally consistent with sulfite reduction and formation of pyrite from reduced organic sulfur, neither of which requires sulfate, the isotopic evidence for an early $(3.47 \mathrm{Ga})$ onset of sulfate reduction 49,50 , suggested based on $\sim 10 \%$ isotopic fractionation ${ }^{51}$, may need to be re-evaluated. Sulfur isotopes are the only reliable tracer for the sulfate reduction metabolism, as preserved cellular structures are not readily identifiable for sulfate-reducers, while molecular fossils (biomarkers) do not seem to survive over geological times ${ }^{49}$. In a low-oxygen world where sulfate was produced in limited quantities ${ }^{52}$ by atmospheric photochemical reactions, and at somewhat greater but uncertain rates by disproportionation of reactive sulfur intermediates 30,52 , dissimilatory sulfate reduction could have become globally competitive for the first time when sulfate concentrations increased in the Neoarchean, following the initial marine oxygenation around $2.7 \mathrm{Ga}^{9,53}$. The observed expansion in $\Delta^{34} \mathrm{~S}_{\mathrm{Fes}}$ beginning around that time ${ }^{5,9}$ thus may reflect not only a more vigorous redox cycling of sulfur but also increased isotopic fractionation $s^{54}$ associated with the expanded range of redox states. Similarly, while anoxygenic phototrophs nearly universally can oxidize sulfide to elemental sulfur ${ }^{24}$, evidence for the evolution of groups capable of completing the oxidation to sulfate seems to appear first around $2.7 \mathrm{Ga}^{55}$. As pyrite could be formed in nonhydrothermal settings from relatively abundant reduced organic sulfur (Fig. 2), its presence may not necessarily indicate active sulfate reduction, allowing a possibility of only trace amounts of sulfate (sulfite) in oceanic seawater. The organic sulfur pathway under such conditions could generate more pyrite than the reduction of seawater sulfate, and the geographic distribution of such pyrite could be broader than for the pyrite formed from hydrothermal $\mathrm{H}_{2} \mathrm{~S}$. The concentrations of dissolved inorganic sulfur in ferruginous oceans thus could have been low enough to make sulfur a co-limiting nutrient, consistent with the approximately similar $\mathrm{S}$ and $\mathrm{P}$ contents in living cells.

Resolving the organic sulfur effects in the Archean rock record requires better understanding of the OS pathways and isotopic fractionations than is currently available. Some insight, however, may be obtained from the expected isotopic signatures (Fig. 3). Assuming that Archean microorganisms satisfied their sulfur requirements by assimilating sulfur with the isotopic composition similar to that of seawater sulfate, the $\Delta^{33} S / \delta^{34} S$ values in the resultant pyrites should fall closer to the $\mathrm{SO}_{4}-\mathrm{S}^{0}$ mixing line (Fig. 3) than those produced through microbial sulfate reduction, which generates stronger $\delta^{34} S$ fractionations. Earlier, organic- 


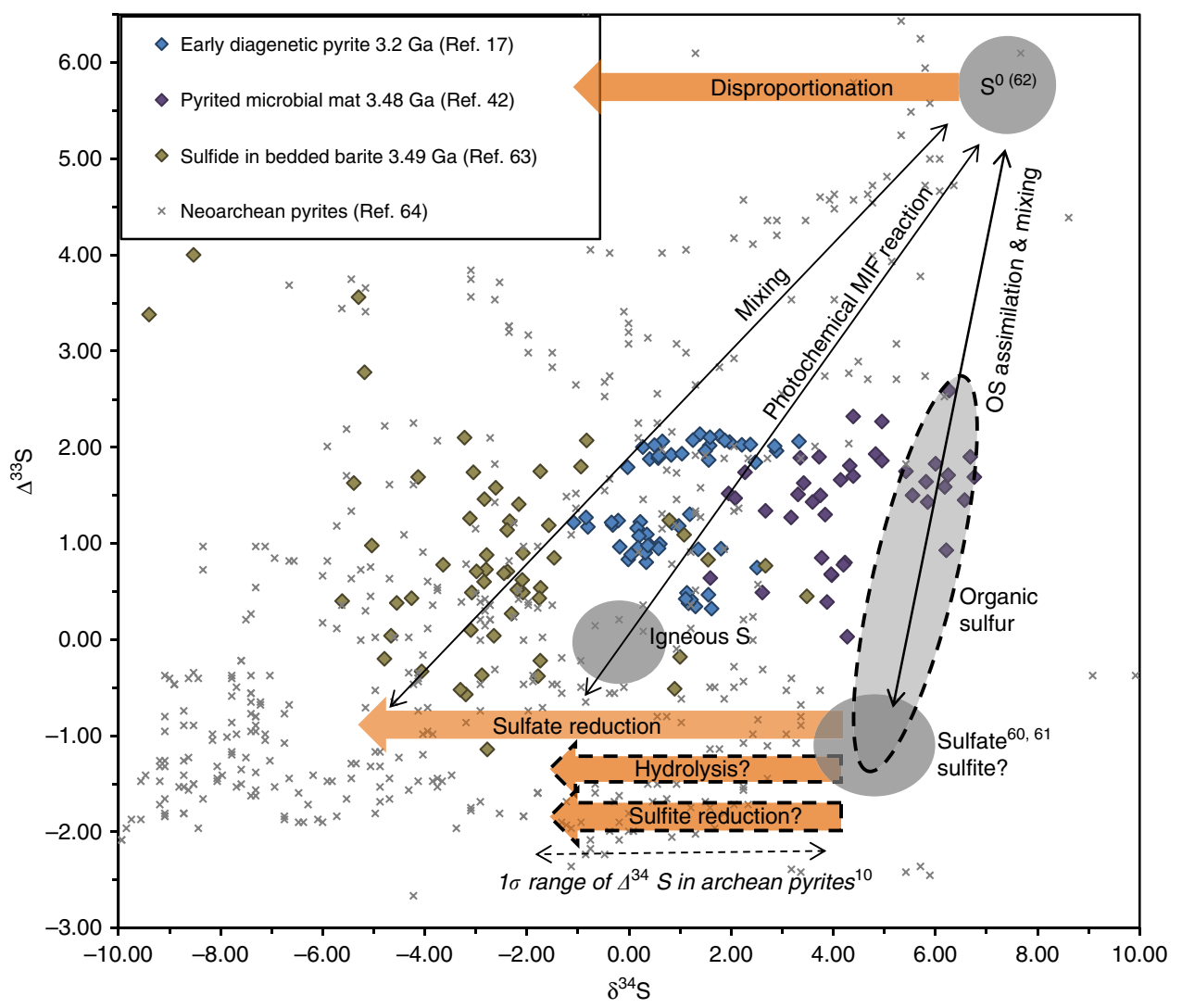

Fig. 3 Summary of potential effects of organic sulfur reactions on the isotopic signatures in Archean pyrites. Symbols illustrate the isotopic data from the literature 10,17,42,60-64 for early (pre-oxygenation) Archean pyrites (blue and purple), Neoarchean pyrites (gray), and sulfide inclusions in sulfate minerals (brown). Gray ovals represent isotopic endmembers; orange arrows denote fractionation-generating microbial reactions. Dashed outlines mark the uncertain contributions and ranges associated with organic sulfur (OS)-specific effects. The poorly constrained $\Delta^{33} S / \delta^{34} S$ composition of the OS pool is plotted here along the sulfate- $\mathrm{S}^{0}$ mixing line to indicate the possibility of Archean organisms assimilating sulfur from either the seawater sulfate (or sulfite) or atmospherically derived elemental sulfur endmembers. Increased sulfate reduction induced by the Neoarchean ocean oxygenation would be expected to increase $\Delta^{34} \mathrm{~S}$, as sulfate reduction produces stronger isotopic fractionations than OS hydrolysis, reduction of sulfite, or $\mathrm{S}$ disproportionation. Errors associated with the data points can be found in the original publications (refs. $10,17,42,60-64$ ) from which the data were taken

rich, or sulfate-poor deposits therefore would be expected to have higher pyritic $\delta^{34} S$ values than those that formed at higher sulfate concentrations, such as in the Neoarchean. While the small amount of Mesoarchean data does not yet allow firm conclusions, this trend seems to be indeed present (Fig. 3). Further insights are likely to be obtained through a combination of laboratory experiments and observations in modern low sulfate environments. In particular, mineral grain-scale signatures ${ }^{17,42}$ of pyriteforming OS mineralization may be potentially resolved when the OS pathways are better characterized for the conditions of low ambient sulfate, and the associated isotopic fractionations, including those during OS hydrolysis, are better determined.

\section{Methods}

Geochemical model. The geochemical reaction-transport model for the transformations of organic sulfur and sediment sulfur cycling was adapted from ref. ${ }^{11}$, with the aspects pertaining to Archean conditions adjusted based on ref. ${ }^{9}$. The included reactions and their rate formulations are listed in Supplementary Tables 1 and 2. Model parameter values are listed in Supplementary Table 3.

Mineralization of organic carbon and the distributions of iron within the sediment were modeled as described in ref. ${ }^{9}$, and their control parameters were varied in the sensitivity analysis (see below). Diagenetic formation of elemental sulfur was considered through oxidation of sulfide by iron oxides, which is the pathway that is thermodynamically favorable at low sulfide concentrations 9 . Thiosulfate was not considered because at low sulfide availability aerobic oxidation of sulfide proceeds largely without intermediate redox compounds ${ }^{24}$.

Mineralization of reduced OS was assumed in the model to generate hydrogen sulfide (Supplementary Table 1) whereas mineralization of oxidized organic sulfur ( $\mathrm{R}-\mathrm{O}-\mathrm{SO}_{3} \mathrm{H}$ groups) such as in sulfonates and esters was assumed to generate sulfite or sulfate. As the S:C ratios in the Archean ecosystem are not established, the $S: C$ ratio was varied in the model within a range of literature values for modern marine ecosystems ${ }^{56}$. The S:C ratios may reflect, for example, factors such as organism physiology (specific sulfur requirements for biomass) and environmental conditions such as nutrient limitation. For example, in modern systems, $\mathrm{P}$ limitation in plankton is known to stimulate substitution of sulfolipids (and Nbased lipids) for phospholipids ${ }^{20,21}$, strengthening the sulfur deposition into sediments.

Organic sulfur was assumed to be delivered into the sediment with particulate organic matter. Similarly to treatment in ref. ${ }^{11}$, the rate of organic sulfur mineralization, a multi-step process, was simulated as proportional to the rate of organic $\mathrm{C}$ mineralization. While enzymatic hydrolysis was considered to be influenced by sulfate availability in soil literature ${ }^{57}$, such inhibition was not shown in modern sediments and thus was not included in the model.

To quantify the fraction $(\alpha)$ of sediment $S$ reduction supported by mineralization of organic sulfur, we used the ratio of the depth-integrated rates of sulfate generation and sulfate reduction, corrected for the in-sediment recycling of sulfur by the disproportionation of elemental sulfur and re-oxidation of hydrogen sulfide. To quantify the fraction $(\beta)$ of pyrite precipitation supported by organic sulfur, we used the ratio of the depth-integrated rates of sulfide generation to iron sulfide formation, corrected for the production of sulfide through elemental sulfur disproportionation and reduction of the mineralized oxidized OS. Using $R^{*}$ as the notation for depth-integrated rates of the respective reactions (Supplementary Table 2), the corresponding parameters $\alpha$ and $\beta$ are thus defined as:

$$
\begin{gathered}
\alpha=\frac{R_{\mathrm{PSO} 4}^{*}}{\left(R_{\mathrm{SR}}^{*}+R_{\mathrm{Assim}}^{*}+R_{\mathrm{CH} 4 \text { _SO } 4}^{*}-R_{\mathrm{SOX}}^{*}-0.25 \times R_{\mathrm{Disp}}^{*}\right)} \\
\beta=\frac{R_{\mathrm{PH} 2 \mathrm{~S}}^{*}-R_{\mathrm{SOX}}^{*}}{\left(R_{\mathrm{FeS}}^{*}-0.75 \times R_{\mathrm{Disp}}^{*}\right)}
\end{gathered}
$$

Values of $\alpha$ or $\beta$ greater than 1 would correspond to a situation where mineralization of OS fully supports, respectively, sulfate reduction or pyrite 
precipitation, with the excess inorganic $S$ fluxing out of the sediment. The fraction of sulfur originated from external inorganic sources, such as seawater sulfate or hydrogen sulfide produced from the reduction of seawater sulfate, are given by 1 $\alpha$, and 1- $\beta$. At higher oxygen levels, the calculated value of $\alpha$ is expected to be a conservative estimate of the OS contribution, as oxidation of organic-sourced reduced sulfur would also replenish the sulfate pool.

Sensitivity analysis of the geochemical model. The dependence of model's results on its parameter values was investigated using a sensitivity analysis. The predicted ranges of $\alpha$ and $\beta$ (Fig. 2 and Supplementary Fig. 1) were calculated for multiple parameter sets (at least 10 for each sulfate concentration), by randomly and independently selecting model parameter values within their uncertainty ranges (Supplementary Table 3), assuming uniform probability distributions. For parameters whose uncertainty ranges span several orders of magnitude, such as reaction rate constants, the values were selected assuming uniform probability distributions of their logarithms. The analysis revealed that the conclusions presented in the main manuscript are not sensitive to most parameters including $\mathrm{pH}$, initial age of organic matter deposited into sediment, diffusion coefficients, porosity, burial velocity, rate constants for oxidation of sulfide and FeS precipitation, Monod constants for sulfate reduction $\left(K_{\mathrm{m}}\right)$, and elemental sulfur disproportionation rate constant. The parameters that affected the values of $\alpha$ and $\beta$ most strongly included the sediment organic matter content, sulfur to carbon ratio $(\mathrm{S} / \mathrm{C})$, and the proportion of organic sulfur present in oxidized $\left(f_{\mathrm{SO} 4}\right)$ vs. reduced form $\left(f_{\mathrm{H} 2 \mathrm{~s}}\right)$. The sensitivity of $\alpha$ and $\beta$ to the $\mathrm{S} / \mathrm{C}$ ratio and organic matter content, as well as the typical sediment geochemical profiles are illustrated in Supplementary Figs. 2-4. As expected, higher S:C ratios elevate the production of inorganic sulfur from organic compounds, which in turn, increases the contributions of organic sulfur in supporting $\mathrm{S}$ reduction and pyrite precipitation. Increasing organic matter content also enhances the contribution of OS, as it supports higher OS mineralization rates, even though it also stimulates sulfate reduction, which increases the drawdown of sulfate from overlying water (Supplementary Fig. 3). In difference to previous diagenetic models of sulfur cycling under Archean conditions ${ }^{9,10}$, the sensitivity of the current model was further investigated by considering production of methane through methanogenesis and consumption of methane through aerobic and anaerobic oxidation (AOM) (Supplementary Tables 1 and 2). This affected the values of $\alpha$ and $\beta$ by less than $5 \%$, as at the considered low concentrations of sulfate the kinetics of AOM is too slow to reduce a significant fraction of sulfate. Specifically, for the typical range of the reaction rate constant $k_{\mathrm{CH} 4-\mathrm{SO} 4}$ in Supplementary Table 3, AOM accounted for no more than $4 \%$ of the total sedimentary sulfate reduction, and the porewater sulfate profiles were affected imperceptibly.

Isotopic model. The isotopic model tracked the transformation of sulfur isotopes $\left.{ }^{32} \mathrm{~S},{ }^{33} \mathrm{~S},{ }^{34} \mathrm{~S}\right)$ during diagenesis, including during organic sulfur hydrolysis. Supplementary Fig. 5 illustrates the reactions and isotopic fractionations associated with modeled pathways. Similarly to the previous model $^{9}$, the total rate of sulfate reduction obtained from the geochemical model was partitioned in terms of the individual isotope rates:

$$
R_{32 \mathrm{SR}}+R_{33 \mathrm{SR}}+R_{34 \mathrm{SR}}=R_{\mathrm{SR}}
$$

Approximating $R_{32 \mathrm{SR}}+R_{34 \mathrm{SR}}=0.9924 R_{\mathrm{SR}}$, as the sulfate pool is dominated by ${ }^{32} \mathrm{SO}_{4}(\sim 96 \%)$ and ${ }^{34} \mathrm{SO}_{4}(\sim 4 \%)$, the individual isotope rates were calculated as:

$$
\begin{aligned}
& R_{32 \mathrm{SR}}=\frac{0.9924 \times R_{\mathrm{SR}}}{1+\frac{\eta}{\alpha}} \\
& R_{34 \mathrm{SR}}=\frac{0.9924 \times R_{\mathrm{SR}}}{1+\frac{\alpha}{\eta}}
\end{aligned}
$$

Here, the fractionation factor

$$
\alpha=\frac{R_{32 \mathrm{SR}}\left[{ }^{34} \mathrm{SO}_{4}^{2-}\right]}{R_{34 \mathrm{SR}}\left[{ }^{32} \mathrm{SO}_{4}^{2-}\right]}
$$

describes the preferential use of the lighter isotope, and $\left[{ }^{32} \mathrm{SO}_{4}\right]$ and $\left[{ }^{34} \mathrm{SO}_{4}\right]$ are concentrations. The concentration ratio $\eta=\left[{ }^{34} \mathrm{SO}_{4}{ }^{2-}\right]:\left[{ }^{32} \mathrm{SO}_{4}{ }^{2-}\right]$ is related to the standard $\delta^{34} S$ notation as

$$
\eta=\frac{\delta^{34} \mathrm{SO}_{4}^{2-} \times \frac{{ }^{34} \mathrm{~S}_{\mathrm{CDT}}}{{ }^{32} \mathrm{~S}_{\mathrm{CDT}}}}{1000}+\frac{{ }^{34} \mathrm{~S}_{\mathrm{CDT}}}{{ }^{32} \mathrm{~S}_{\mathrm{CDT}}}
$$

where $\mathrm{CDT}$ refers to the ${ }^{34} \mathrm{~S} /{ }^{32} \mathrm{~S}$-ratio of the standard troilite, an iron monosulfide from the Canyon Diablo Meteroite. The value of $\eta$ at the beginning of iterations was calculated using the $\delta^{34} \mathrm{SO}_{4}{ }^{2-}$ of $12 \%$. For $\alpha$, we conservatively imposed a fractionation factor of $30 \%(\alpha=1.030)$, typical for sulfate reducing bacteria ${ }^{58}$, and decreased it linearly to zero below $6 \mu \mathrm{M}$, which reflects sulfate limitation ${ }^{16}$, similarly to previous models ${ }^{9}, 10$. Constant fractionation factors $(\alpha)$ were used for other reactions: organic sulfur hydrolysis (1.015), sulfide oxidation $^{16}(1.005)$ and elemental sulfur disproportionation ${ }^{59}$ ( 0.988 for sulfate and 1.007 for sulfide).
The reduction rate for ${ }^{33} \mathrm{SO}_{4}{ }^{2-}$ was calculated as:

$$
R_{33 \mathrm{SR}}=R_{32 \mathrm{SR}} \frac{\eta^{\prime}}{\alpha^{\prime}}
$$

with the mass-dependent fractionation factor $\alpha^{\prime}=0.515 \alpha$. The initial value of $\eta^{\prime}=$ $\left[{ }^{33} \mathrm{SO}_{4}{ }^{2-}\right.$ ]: $\left.{ }^{32} \mathrm{SO}_{4}{ }^{2-}\right]$ was calculated using the $\delta^{33} \mathrm{SO}_{4}{ }^{2-}$ of $2.5 \%$ :

To considering isotopic fractionation during organic sulfur hydrolysis, the total rate of hydrolysis obtained from the geochemical model was partitioned in terms of the individual rates of oxidized and reduced organic sulfur:

$$
\begin{aligned}
& R_{32 \mathrm{PSO} 4}+R_{33 \mathrm{PSO} 4}+R_{34 \mathrm{PSO} 4}=R_{\mathrm{PSO} 4} \\
& R_{32 \mathrm{PH} 2 \mathrm{~S}}+R_{33 \mathrm{PH} 2 \mathrm{~S}}+R_{34 \mathrm{PH} 2 \mathrm{~S}}=R_{\mathrm{PH} 2 \mathrm{~S}}
\end{aligned}
$$

The rates and concentrations for the individual isotopes were calculated iteratively analogously to the process described above for sulfate reduction, using defined fractionation factors. Calculations for other reactions in Supplementary Table 1 were carried out similarly to ref. ${ }^{9}$.

To calculate vertical concentration profiles, net rates were expressed as follows:

$$
\begin{gathered}
\mathrm{NR}^{32} \mathrm{SO}_{4}^{2-}=R_{32 \mathrm{SR}}-R_{32 \mathrm{SOX}}-R_{32 \mathrm{Disp}\left(\mathrm{SO}_{4}\right)}-R_{32 \mathrm{PSO} 4} \\
\mathrm{NR}^{33} \mathrm{SO}_{4}^{2-}=R_{33 \mathrm{SR}}-R_{33 \mathrm{SOX}}-R_{33 \mathrm{Disp}\left(\mathrm{SO}_{4}\right)}-R_{33 \mathrm{PSO} 4} \\
\mathrm{NR}^{34} \mathrm{SO}_{4}^{2-}=R_{34 \mathrm{SR}}-R_{34 \mathrm{SOX}}-R_{34 \mathrm{Disp}\left(\mathrm{SO}_{4}\right)}-R_{34 \mathrm{PSO} 4} \\
\mathrm{NRH}_{2}{ }^{32} \mathrm{~S}= \\
R_{32 \mathrm{SOX}}+R_{32 \mathrm{FeS}}+R_{32 \mathrm{~S}^{0}}+R_{32 \mathrm{FeS}+\mathrm{HS}}-R_{32 \mathrm{SR}}-R_{32 \mathrm{Disp}\left(\mathrm{H}_{2 \mathrm{~S}}\right)}-R_{32 \mathrm{PH} 2 \mathrm{~S}}
\end{gathered}
$$

$\mathrm{NRH}_{2}{ }^{33} \mathrm{~S}=R_{33 \mathrm{SOX}}+R_{33 \mathrm{FeS}}+R_{33 \mathrm{~S}^{0}}+R_{33 \mathrm{FeS}+\mathrm{HS}}-R_{33 \mathrm{SR}}-R_{33 \mathrm{Disp}\left(\mathrm{H}_{2 \mathrm{~S}}\right)}-R_{33 \mathrm{PH} 2 \mathrm{~S}}$

$\mathrm{NRH}_{2}{ }^{34} \mathrm{~S}=R_{34 \mathrm{SOX}}+R_{34 \mathrm{FeS}}+R_{34 \mathrm{~S}^{0}}+R_{34 \mathrm{FeS}+\mathrm{HS}}-R_{34 \mathrm{SR}}-R_{34 \mathrm{Disp}\left(\mathrm{H}_{2 \mathrm{~S}}\right)}-R_{34 \mathrm{PH} 2 \mathrm{~S}}$

$$
\begin{aligned}
& \mathrm{NR}^{32} \mathrm{~S}^{0}=R_{32 \mathrm{~S}^{0}}-\left(R_{32 \mathrm{Disp}\left(\mathrm{H}_{25}\right)}+R_{32 \mathrm{Disp}\left(\mathrm{SO}_{4}\right)}\right)-R_{32 \mathrm{FeS}+\mathrm{S}} \\
& \mathrm{NR}^{33} \mathrm{~S}^{0}=R_{33 \mathrm{~S}^{0}}-\left(R_{33 \mathrm{Disp}\left(\mathrm{H}_{25}\right)}+R_{33 \mathrm{Disp}\left(\mathrm{SO}_{4}\right)}\right)-R_{33 \mathrm{FeS}+\mathrm{S}} \\
& \mathrm{NR}^{34} \mathrm{~S}^{0}=R_{34 \mathrm{~S}^{0}}-\left(R_{34 \mathrm{Disp}\left(\mathrm{H}_{25}\right)}+R_{34 \mathrm{Disp}\left(\mathrm{SO}_{4}\right)}\right)-R_{34 \mathrm{FeS}+\mathrm{S}}
\end{aligned}
$$

The vertical gradients and concentrations for each isotope were then computed by integrating the diagenetic equations over depth with the rates given by Eqs. (11-19). The concentrations, rates, and isotopic ratio parameters were recalculated iteratively until convergence was reached. The isotopic composition of $\mathrm{FeS}_{2}$ was then found by integrating the $\mathrm{FeS}_{2}$ precipitation rates for individual isotopes. Based on the diagenetic equations with $D_{i}=0$ :

$$
\begin{aligned}
& {\left[\mathrm{Fe}^{34} \mathrm{~S}_{2}\right]=\frac{\int_{0}^{l}\left(R_{34 \mathrm{FeS}+\mathrm{S}}+R_{34 \mathrm{FeS}+\mathrm{HS}}\right) \cdot \mathrm{d} x}{v}} \\
& {\left[\mathrm{Fe}^{33} \mathrm{~S}_{2}\right]=\frac{\int_{0}^{l}\left(R_{33 \mathrm{FeS}+\mathrm{S}}+R_{33 \mathrm{FeS}+\mathrm{HS}}\right) \cdot \mathrm{d} x}{v}} \\
& {\left[\mathrm{Fe}^{32} \mathrm{~S}_{2}\right]=\frac{\int_{0}^{l}\left(R_{32 \mathrm{FeS}+\mathrm{S}}+R_{32 \mathrm{FeS}+\mathrm{HS}}\right) \cdot \mathrm{d} x}{v}}
\end{aligned}
$$

Sensitivity analysis of the isotopic model. The sensitivity of the isotopic simulation results to model parameters was performed similarly to the sensitivity analysis of the geochemical model. While the results are mostly similar to the findings described in ref. ${ }^{9}$, isotopic fractionation during organic sulfur hydrolysis affects the isotopic composition of pyrite. Specifically, preferential mineralization of isotopically light organic sulfur results in an isotopically lighter pyrite. As a result, the isotopic composition of pyrite deviates more from that of the seawater sulfate, resulting in a greater $\Delta^{34} S_{\mathrm{FeS} 2}$ (by up to $7 \%$ ) (Supplementary Fig. 6). This effect is more pronounced at higher sulfur to carbon ratios where the contribution of organic sulfur hydrolysis is greater (Supplementary Fig. 6). At higher sulfate concentrations, the isotopic composition of pyrite is less affected (Supplementary Fig. 6).

Organic sulfur does not strongly affect the mass independent fractionation of sulfur (MIF-S), characteristic of Archean pyrites. The atmospherically produced MIF-S signal is transmitted from elemental $\mathrm{S}$ to pyrite through diagenesis and is influenced by the isotopic composition of iron sulfide and porewater sulfide ${ }^{9}$. Because sulfide can be generated from non-MIF-S sulfate through sulfate reduction and hydrolysis of reduced organic sulfur, its addition to pyrite dilutes the MIF-S signal. While the contribution of organic sulfur slightly increases the amount of sulfide with mass-dependent fractionation, our modeling results indicate that its effect on the $\Delta^{33} \mathrm{~S}$ value of pyrite is less than $0.5 \%$. 


\section{Data availability}

The authors declare that data supporting the findings of this study are available within this article and its Supplementary Information, and all additional data are available from the corresponding author on reasonable request.

Received: 13 July 2018; Accepted: 6 September 2019; Published online: 07 October 2019

\section{References}

1. Martin, W., Baross, J., Kelley, D. \& Microbiology, M. R.-N. R. Hydrothermal vents and the origin of life. Nat. Rev. Microbiol. 6, 805 (2008).

2. Sievert, S., Kiene, R. \& Schulz-Vogt, H. N. The sulfur cycle. Oceanography 20, 117-123 (2007).

3. Eigenbrode, J. L. et al. Organic matter preserved in 3-billion-year-old mudstones at Gale crater, Mars. Science 360, 1096-1101 (2018).

4. Ksionzek, K. B. et al. Dissolved organic sulfur in the ocean: biogeochemistry of a petagram inventory. Science 354, 456-459 (2016).

5. Canfield, D. E. \& Farquhar, J. Animal evolution, bioturbation, and the sulfate concentration of the oceans. Proc. Natl Acad. Sci. USA 106, 8123-8127 (2009).

6. Fakhraee, M., Hancisse, O., Canfield, D. E., Crowe, S. A. \& Katsev, S. Proterozoic seawater sulfate scarcity and the evolution of ocean-atmosphere chemistry. Nat. Geosci. 12, 375-380 (2019).

7. Newton, R. J. et al. Low marine sulfate concentrations and the isolation of the European epicontinental sea during the Early Jurassic. Geology 39, 7-10 (2011).

8. Eickmann, B. et al. Isotopic evidence for oxygenated Mesoarchaean shallow oceans. Nat. Geosci. 11, 133-138 (2018).

9. Fakhraee, M., Crowe, S. A. \& Katsev, S. Sedimentary sulfur isotopes and neoarchean ocean oxygenation. Sci. Adv. 4, e1701835 (2018).

10. Crowe, S. A. et al. Sulfate was a trace constituent of Archean seawater. Science 346, 735-739 (2014).

11. Fakhraee, M., Li, J. \& Katsev, S. Significant role of organic sulfur in supporting sedimentary sulfate reduction in low-sulfate environments. Geochim. Cosmochim. Acta 213, 502-516 (2017).

12. King, G. M. \& Klug, M. J. Comparative aspects of sulfur mineralization in sediments of a eutrophic lake basin. Appl. Environ. Microbiol. 43, 1406-1412 (1982).

13. Cook, R. B. \& Schindler, D. W. The biogeochemistry of sulf acidified lake. Ecol. Bull. 115-127 https://doi.org/10.2307/20112848 (1983).

14. Nriagu, J. O. Sulfur metabolism and sedimentary environment: Lake Mendota, Wisconsin. Limnol. Oceanogr. 13, 430-439 (1968).

15. Johnston, D. T. Multiple sulfur isotopes and the evolution of Earth's surface sulfur cycle. Earth-Science Rev. 106, 161-183 (2011).

16. Habicht, K. S., Gade, M., Thamdrup, B., Berg, P. \& Canfield, D. E. Calibration of sulfate levels in the archean ocean. Science 298, 2372-2374 (2002).

17. Galić, A. et al. Pyrite in a sulfate-poor Paleoarchean basin was derived predominantly from elemental sulfur: Evidence from $3.2 \mathrm{Ga}$ sediments in the Barberton Greenstone Belt, Kaapvaal Craton. Chem. Geol. 449, 135-146 (2017).

18. Ho, T.-Y. et al. The elemental composition of some marine phytoplankton. J. Phycol. 39, 1145-1159 (2003).

19. Fagerbakke, K., Heldal, M. \& Norland, S. Content of carbon, nitrogen, oxygen, sulfur and phosphorus in native aquatic and cultured bacteria. Aquat. Microb. Ecol. 10, 15-27 (1996).

20. Bellinger, B. J. et al. Physiological modifications of seston in response to physicochemical gradients within Lake Superior. Limnol. Oceanogr. 59, 1011-1026 (2014).

21. Van Mooy, B. A. S., Rocap, G., Fredricks, H. F., Evans, C. T. \& Devol, A. H. Sulfolipids dramatically decrease phosphorus demand by picocyanobacteria in oligotrophic marine environments. Proc. Natl Acad. Sci. USA 103, 8607-8612 (2006).

22. Reinhard, C. T. et al. Evolution of the global phosphorus cycle. Nature 541, 386-389 (2017).

23. Havig, J. R., Hamilton, T. L., Bachan, A. \& Kump, L. R. Sulfur and carbon isotopic evidence for metabolic pathway evolution and a four-stepped Earth system progression across the Archean and Paleoproterozoic. Earth-Sci. Rev. 174, 1-21 (2017).

24. Canfield, D. E., Kristensen, E. \& Thamdrup, B. The sulfur cycle. Adv. Mar. Biol. 48, 313-381 (2005).

25. Levine, N. M. Putting the spotlight on organic sulfur. Science 354, 418-419 (2016).

26. Vairavamurthy, A., Zhou, W., Eglinton, T. \& Manowitz, B. Sulfonates: a novel class of organic sulfur compounds in marine sediments. Geochim. Cosmochim. Acta 58, 4681-4687 (1994).

27. Heinen, W. \& Lauwers, A. M. Organic sulfur compounds resulting from the interaction of iron sulfide, hydrogen sulfide and carbon dioxide in an anaerobic aqueous environment. Orig. Life Evol. Biosph. 26, 131-150 (1996).
28. Cody, G. D. et al. Primordial carbonylated iron-sulfur compounds and the synthesis of pyruvate. Science 289, 1337-1340 (2000).

29. Findlay, A. J. \& Kamyshny, A. Turnover rates of intermediate sulfur species (Sx2-,S0, S2O32-, S4O62-, SO32-) in anoxic freshwater and sediments. Front. Microbiol. 8, 2551 (2017)

30. Zopfi, J., Ferdelman, T. G., Fossing, H. Distribution and fate of sulfur intermediates-sulfite, tetrathionate, thiosulfate, and elemental sulfur-in marine sediments. in Sulfur Biogeochemistry: Past and Present (eds. Amend, J. P., Edwards K. J., Lyons T. W.) (Geological Society of America Special Paper 379, p. 97-116, 2004).

31. Finster, K. Microbiological disproportionation of inorganic sulfur compounds. J. Sulfur Chem. 29, 281-292 (2008).

32. Habicht, K. S., Canfield, D. E. \& Rethmeier, J. Sulfur isotope fractionation during bacterial reduction and disproportionation of thiosulfate and sulfite. Geochim. Cosmochim. Acta 62, 2585-2595 (1998).

33. Knoll, A. H., Bergmann, K. D. \& Strauss, J. V. Life: the first two billion years. Philos. Trans. R. Soc. B Biol. Sci. 371, 20150493 (2016).

34. Schulz, H. D., Zabel, M., E. in Marine Geochemistry. (Springer-Verlag, 2006)

35. David, L. A. \& Alm, E. J. Rapid evolutionary innovation during an Archaean genetic expansion. Nature 469, 93-96 (2011).

36. Rabus, R., Hansen, T. A. \& Widdel, F. Dissimilatory sulfate- and sulfurreducing prokaryotes. in The Prokaryotes 309-404 (Springer Berlin Heidelberg, 2013).

37. Canfield, D. E., Rosing, M. T. \& Bjerrum, C. Early anaerobic metabolisms Phil. Trans. R. Soc. https://doi.org/10.1098/rstb.2006.1906 (2006).

38. del Giorgio, P. A. \& Duarte, C. M. Respiration in the open ocean. Nature 420 379-384 (2002).

39. Poulton, S. W. \& Canfield, D. E. Ferruginous conditions: a dominant feature of the ocean through earth's history. Elements 7, 107-112 (2011).

40. Laakso, T. A. \& Schrag, D. P. A theory of atmospheric oxygen. Geobiology 15 366-384 (2017)

41. Canfield, D. E. The evolution of the earth surface sulfur reservoir. Am. J. Sci. 304, 839-861 (2004).

42. Wacey, D., Noffke, N., Cliff, J., Barley, M. E. \& Farquhar, J. Micro-scale quadruple sulfur isotope analysis of pyrite from the 23480 Ma Dresser Formation: New insights into sulfur cycling on the early Earth. Precambrian Res. 258, 24-35 (2015).

43. Olson, S. L., Kump, L. R. \& Kasting, J. F. Quantifying the areal extent and dissolved oxygen concentrations of Archean oxygen oases. Chem. Geol. 362 35-43 (2013).

44. Leavitt, W. D. et al. Multiple sulfur isotope signatures of sulfite and thiosulfate reduction by the model dissimilatory sulfate-reducer, Desulfovibrio alaskensis str. G20. Front. Microbiol. 5, 591 (2014).

45. Saunders, W. H. Organic sulfur compounds, Vol. I. in Organic Sulfur Compounds (ed. Kharasch, N.) 624 (Elsevier, 1967).

46. Burlingham, B. T. et al. $34 \mathrm{~S}$ Isotope effect on sulfate ester hydrolysis: mechanistic implications. J. Am. Chem. Soc. 125, 13036-13037 (2003).

47. Canfield, D. E., Boudreau, B. P., Mucci, A. \& Gundersen, J. K. The early diagenetic formation of organic sulfur in the sediments of Mangrove Lake, Bermuda. Geochim. Cosmochim. Acta 62, 767-781 (1998).

48. Raven, M. R., Sessions, A. L., Fischer, W. W. \& Adkins, J. F. Sedimentary pyrite $\delta 34 \mathrm{~S}$ differs from porewater sulfide in Santa Barbara Basin: proposed role of organic sulfur. Geochim. Cosmochim. Acta 186, 120-134 (2016).

49. Shen, Y. \& Buick, R. The antiquity of microbial sulfate reduction. Earth-Sci. Rev. 64, 243-272 (2004)

50. Aoyama, S. \& Ueno, Y. Multiple sulfur isotope constraints on microbial sulfate reduction below an Archean seafloor hydrothermal system. Geobiology 16, 107-120 (2018)

51. Bottrell, S. H. \& Newton, R. J. Reconstruction of changes in global sulfur cycling from marine sulfate isotopes. Earth-Science Rev. 75, 59-83 (2006).

52. Halevy, I. Production, preservation, and biological processing of massindependent sulfur isotope fractionation in the Archean surface environment. Proc. Natl Acad Sci. 110, 17644-17649 (2013).

53. Blank, C. E. Evolutionary timing of the origins of mesophilic sulphate reduction and oxygenic photosynthesis: a phylogenomic dating approach. Geobiology 2, 1-20 (2004).

54. Marin-Carbonne, J. et al. Sulfur isotope's signal of nanopyrites enclosed in 2.7 Ga stromatolitic organic remains reveal microbial sulfate reduction. Geobiology 16, 121-138 (2018).

55. Hohmann-Marriott, M. F. \& Blankenship, R. E. Evolution of photosynthesis. Annu. Rev. Plant Biol. 62, 515-548 (2011)

56. Burdige, D. J. Geochemistry of Marine Sediments. (Princeton University Press, 2006).

57. Scherer, H. W. Sulfur in soils. J. Plant Nutr. Soil Sci. 172, 326-335 (2009)

58. Canfield, D. E. Isotope fractionation by natural populations of sulfatereducing bacteria. Geochim. Cosmochim. Acta 65, 1117-1124 (2001).

59. Canfield, D. E. \& Thamdrup, B. The production of 34 S-depleted sulfide during bacterial disproportionation of elemental sulfur. Science 266, 1973-1975 (1994). 
60. Ueno, Y., Ono, S., Rumble, D. \& Maruyama, S. Quadruple sulfur isotope analysis of ca. 3.5 Ga Dresser Formation: New evidence for microbial sulfate reduction in the early Archean. Geochim. Cosmochim. Acta 72, 5675-5691 (2008).

61. Shen, Y., Farquhar, J., Masterson, A., Kaufman, A. J. \& Buick, R. Evaluating the role of microbial sulfate reduction in the early Archean using quadruple isotope systematics. Earth Planet. Sci. Lett. 279, 383-391 (2009).

62. Ono, S. et al. New insights into Archean sulfur cycle from mass-independent sulfur isotope records from the Hamersley Basin, Australia. Earth Planet. Sci. Lett. 213, 15-30 (2003).

63. Philippot, P. et al. Early Archaean microorganisms preferred elemental sulfur, not sulfate. Science 317, 1534-1537 (2007)

64. Zhelezinskaia, I., Kaufman, A. J., Farquhar, J. \& Cliff, J. Large sulfur isotope fractionations associated with Neoarchean microbial sulfate reduction. Science 346, 742-744 (2014).

\section{Acknowledgements}

This work benefited from partial support from NSF EAR grants 1754061 and 1660873. M.F. acknowledges support in the form of a summer fellowship from the UMN Water Resources Science Graduate Program and teaching assistantship from the UMD Department of Physics and Astronomy.

\section{Author contributions}

M.F. and S.K. conceived the ideas and co-wrote the paper. M.F. performed the numerical simulations.

\section{Competing interests}

The authors declare no competing interests.

\section{Additional information}

Supplementary information is available for this paper at https://doi.org/10.1038/s41467019-12396-y.

Correspondence and requests for materials should be addressed to M.F. or S.K.

Peer review information Nature Communications thanks Boswell Wing and the other, anonymous, reviewer(s) for their contribution to the peer review of this work.

Reprints and permission information is available at http://www.nature.com/reprints

Publisher's note Springer Nature remains neutral with regard to jurisdictional claims in published maps and institutional affiliations.

(c) (i) Open Access This article is licensed under a Creative Commons Attribution 4.0 International License, which permits use, sharing, adaptation, distribution and reproduction in any medium or format, as long as you give appropriate credit to the original author(s) and the source, provide a link to the Creative Commons license, and indicate if changes were made. The images or other third party material in this article are included in the article's Creative Commons license, unless indicated otherwise in a credit line to the material. If material is not included in the article's Creative Commons license and your intended use is not permitted by statutory regulation or exceeds the permitted use, you will need to obtain permission directly from the copyright holder. To view a copy of this license, visit http://creativecommons.org/ licenses/by/4.0/.

(C) The Author(s) 2019 